\title{
El debate sobre el futuro de la especie humana: Habermas critica la eugenesia liberal *
}

\author{
EDUARDO MENDIETA \\ Universidad del Estado de Nueva York en Stony Brook
}

RESUMEN. En este artículo se discute el reciente libro de Jürgen Habermas, Die Zukunft der menschlichen Natur. Auf dem Weg zu einer liberalen Eugenik (Suhrkamp Verlag, 2001). Se presta especial atención al argumento central relacionado con los efectos negativos que podría tener la aceptación general de la clonación y el diagnóstico génico preimplantacional (DGP) sobre la autocomprensión moral y política de las generaciones presentes y futuras. $\mathrm{La}$ discusión continúa con una crítica a los argumentos centrales de Habermas contra el DGP, y desarrolla al menos dos razonamientos que están en armonía con su defensa general de la democracia procedimental y la moral deontológica. Se apela a Peter Singer y John Rawls para desarrollar argumentos que no se oponen ni al DGP ni a la ingeniería genética y que, no obstante, están totalmente de acuerdo con el espíritu de la modernidad política, tal y como lo defiende y define Habermas. La conclusión insta a una crítica de las biotecnologías desencadenadas por la revolución de la información que tenga un carácter menos moralizante y más político-económico.
ABSTRACT. Jürgen Habermas's recent book Die Zukunft der menschlichen Natur. Auf dem Weg zu einer liberalen Eugenik (Suhrkamp Verlag, 2001) is discussed. Particular attention is paid to the central argument concerning the adverse effects the general acceptance of cloning and pre-implantation genetic diagnostics (PGD) would have on the moral and political self-understanding of present and future generations. The argument turns to a critique of Habermas's central arguments against PGD, and develops at least two arguments that are in harmony with his general defense of procedural democracy and deontological morality. Appeal is made to Peter Singer and John Rawls to develop arguments that do not reject either PGD or genetic engineering and that are nonetheless in full compliance with the spirit of political modernity, as is defended and defined by Habermas. The conclusion calls for less moralizing and more political-economic critique of the biotechnologies unleashed by the information revolution.

«Shallow are the souls that have forgotten how to shudder» (Leon Kass, «The Wisdom of Repugnance») ${ }^{1}$

* Traducción de Marta I. González.

${ }^{1}$ Leon Kass, «The Wisdom of Repugnance», en Gregory E. Pence (ed.), Flesh of my Flesh: The Ethics of Cloning Humans. A Reader, Lantham, MD, Rowman \& Littlefield Publishers, 1998, p. 21. [«Son frívolas las almas que han olvidado cómo estremecerse», N. de la T.]. 
«Das Leen im moralischen Vakuum, in einter Lebensform, die nicht enmal mehr moralischen Zynismus kennen würde, wäre nich lebeswert» (Jürgen Habermas, «Auf dem Weg zu einer liberalen Eugenik?») ${ }^{2}$

Los avances recientes en biotecnología han desencadenado una avalancha de reflexiones, debates y especulaciones que van desde la habitual retórica apocalíptica sobre un «mundo feliz» genético hasta la tecnofilia triunfante que describe cualquier intento de regulación como un modo de bloquear el merecido camino hacia una sociedad futura más humana, y quizás incluso más justa. Desde el punto de vista de una de las partes, nos enfrentamos a una forma brutal y sofisticada de eugenesia, respaldada en nuestros días por el discurso del neoliberalismo y la medicina comercializada; pero la otra parte argumenta con el mismo énfasis y convicción que, del mismo modo que la revolución verde impulsada por la biotecnología puede solucionar el hambre en el mundo, la genómica puede resolver también los problemas de delincuencia y pobreza en la sociedad. Las situaciones hipotéticas a las que ambas partes apelan se convierten rápidamente en escenarios de ciencia-ficción que pueden tomarse con facilidad como retratos de lo que no solamente es probable que ocurra, sino incluso inevitable. De hecho, se ha vuelto una tarea difícil discernir la ciencia-ficción de los hechos, las situaciones hipotéticas de las situaciones que ya se dan en el trabajo de los laboratorios. Como era de esperar, estos debates se han extendido a cualquier esfera imaginable de la reflexión y la preocupación humanas. La teoría política, la teoría jurídica, la teoría moral, la filosofía social, la psicología, la historia de la ciencia, la filosofía de la tecnología, los estudios sobre discapacidades, incluso el arte; la lista es, en efecto, interminable, y cada uno de estos horizonte de la reflexión humana ha recibido el impacto de las posibilidades, y las improbabilidades, desencadenadas por los avances en biotecnología representados paradigmáticamente en la clonación de la oveja Dolly. Además, todos estos campos han recibido este impacto en su mismo núcleo, porque la biotecnología y las técnicas de intervención genética a disposición de los médicos han alterado cualitativamente nuestra autocomprensión como seres humanos. Los desarrollos científicos y tecnológicos han alcanzado niveles tales de sofisticación, estilización y especialización que no tenemos más remedio que hablar, no de una simple acumulación cuantitativa, sino de un salto cualitativo. Por vez primera, nuestra propia esencia, o naturaleza, humana está disponible para manipulaciones tecnológicas directas. Lo que está en juego ya no es la adaptación de un avance tecnológico a nuestras autocomprensiones y realidades sociopolíticas, sino la reflexión sobre nuestra propia autocomprensión como especie a la luz de un avance tecnológico que pone en cuestión lo que significa ser humano. Hubo un tiempo en el que la tecnología se utilizaba

2 Jürgen Habermas, Die Zukunft der menschlichen Natur. Auf dem Weg zu einer liberalen Eugenik?, Frankfurt am Main, Suhrkamp, 2001, pp. 124-125. [«La vida en un vacío moral, como una vida desprovista incluso de cinismo, no merecería la pena ser vivida», N. de la T.]. 
para modelar el intransigente mundo natural a nuestra imagen y según nuestros planes y deseos. Ahora nos hemos convertido en objeto de manipulaciones tecnológicas - nos hemos convertido en nuestras propias herramientas-. Debido a esto, la biotecnología y su aplicación a los humanos, la genómica, exige que reflexionemos sobre lo que significa ser humano en una época en la que la naturaleza humana es tierra de nadie.

Habermas ha intervenido en este diálogo con un texto enérgico, oportuno y provocador: Die Zukunft der menschlichen Natur. Auf dem Weg zu einer liberalen Eugenik [El futuro de la naturaleza humana. ¿Hacia una eugenesia liberal?] ${ }^{3}$. Este libro apareció en el otoño de 2001 en medio de la celebración y el debate sobre la concesión a Habermas del Premio de la Paz de la Asociación de Libreros Alemanes. El libro también aparece en la estela de otro debate en Alemania, a saber, el debate que no fue tal debate entre Peter Sloterdijk y Habermas. Considero que es importante tener en cuenta el (no) debate Sloterdijk como trasfondo, ya que determina, en mi opinión, la naturaleza misma de la respuesta de Habermas. En otras palabras, aunque El futuro de la naturaleza humana de Habermas no es un enfrentamiento frontal y explícito con Sloterdijk, sí es un rechazo implícito y tangencial de lo que éste representa. Al principio del texto, Habermas rechaza explícitamente la retórica hiperbólica de los autodenominados nietzscheanos que yuxtaponen la «hipermodernidad» a una «hipermoralidad» que tiene demasiadas reminiscencias de la vieja ideología de los mandarines alemanes (43). En contraposición a estos poshumanistas, Habermas sugiere que deberíamos reflexionar a un nivel más bajo de abstracción, un nivel que esté más en consonancia con nuestra modernidad reflexiva. Éste es el nivel al que podemos considerar el impacto práctico que la intervención genética, y aquí a Habermas le interesa especialmente la investigación con células madre y el diagnóstico génico preimplantacional (DGP), podría tener sobre la autocomprensión moral de las generaciones futuras objeto de las intervenciones con DGP. De un modo más específico, se trata de considerar qué consecuencias tendría para la modernidad política que se nos permitiera proseguir con la optimización e instrumentalización de la especie que suponen todas las formas de intervención genética. En la primera parte de este ensayo presentaré algunos de los argumentos centrales que Habermas desarrolla para rechazar una eugenesia liberal (I). En la segunda parte, articularé algunas objeciones y críticas a la posición habermasiana (II). Concluiré en la parte final con algunas formulaciones positivas que trasladan la crítica y el diálogo a un nivel diferente de argumentación (III).

${ }^{3}$ Jürgen Habermas, El futuro de la naturaleza humana. ¿Hacia una eugenesia liberal?, trad. de R. S. Carbó, Barcelona, Paidós, 2002. De ahora en adelante citaré en el texto las páginas de esta traducción. 


\section{I. «El debate sobre la autocomprensión ética de la especie»}

En este punto es preciso comenzar con algunas observaciones preliminares sobre el fascinante texto de Habermas. En primer lugar, aunque el libro no lleva ni en el título ni en el subtítulo la descripción «Keline Politische Schriften» [Breves escritos políticos] que hemos terminado asociando con los textos más polémicos de Habermas, se trata claramente de un texto político. No es un trabajo estrictamente filosófico o de teoría social. En este extenso ensayo, los argumentos filosóficos, o la referencia a argumentos y textos filosóficos, se presentan únicamente para apoyar argumentos políticos acerca de cómo deberíamos abordar las intervenciones genéticas desde una perspectiva jurídico-política. En segundo lugar, aunque no es un texto estrictamente filosófico, defiende algunas tesis nuevas que sorprenderán a muchos de los lectores de Habermas. De hecho, algunos de los argumentos en contra de las intervenciones y cribados genéticos lograrán que muchos de sus críticos simpaticen más con Habermas, en especial aquellos que le habían instado a prestar más atención a la corporalidad de los sujetos éticos. La fuerza polémica del texto, sin embargo, eclipsa estos provocadores argumentos filosóficos que quizá recuerdan demasiado a la antropología filosófica que Habermas favorecía en su juventud, cuando trabajaba en el fundamento cognitivo-antropológico de los intereses de conocimiento. En otras palabras, hay algunos argumentos muy peculiares que nos pueden inducir a pensar que Habermas podría estar dando otro giro filosófico, en este caso desde un paradigma filosófico posmetafísico hacia una metafísica cuasiaristotélica de las sustancias y las esencias disfrazada como una ética de la especie. Volveré más adelante sobre este punto. De momento, presentaré lo que entiendo como una reconstrucción complaciente de los principales argumentos de Habermas.

Habermas sostiene que no ha habido un debate público serio sobre si deberíamos prohibir todos los diagnósticos génicos preimplantacionales ${ }^{4}$. Los ciudadanos se han rendido a la perspectiva cínica según la cual los desarrollos en medicina y biotecnología están impulsados por el mercado, y al credo liberal según el cual las decisiones relativas a la procreación han de dejarse a la voluntad individual de los ciudadanos. Hasta el momento, cualquier debate público ha terminado estancándose debido a la presuposición de que las disciplinas y tecnologías médicas tienen como objetivo ampliar el abanico de tecnologías reproductivas disponibles para los individuos. Pero Habermas insiste en que no nos abandonemos ni al cinismo ni a las metaespeculaciones autoaislantes de los poshumanistas como Sloterdijk. Debemos ser capaces de desarrollar principios y normas que nos permitirán tomar decisiones normativas sobre

${ }^{4}$ Véase el excelente artículo de Bonnie Steinbock, «Preimplantation Genetic Diagnosis and Embryo Selection», en Justine Burley y John Harris (eds.), A Companion to Genethics, Malden, Mass, Blackwell Publishers, 2002, pp. 175-190. 
lo que debería y no debería ocurrir con la optimización y mejora de la humanidad. La tragedia sería enfrentarse a un mundo en el que las decisiones sobre lo que queremos para nosotros y para nuestros hijos estuvieran ya dadas por el hecho consumado de las transformaciones tecnológicas del genoma humano. Sin embargo, Habermas también es sensible a las dificultades que se encuentran al tratar de desarrollar cualquier tipo de argumento que implique la prohibición o limitación del acceso a tecnologías que pudieran suponer un alivio del dolor y el sufrimiento causado por las enfermedades congénitas. De hecho, no hay ninguna frontera natural que separe las intervenciones médicas encaminadas a eliminar la enfermedad de las que simplemente buscan mejorar las vidas de los pacientes. Lo mismo podría decirse del cribado y la terapia génica.

A la vista de estos retos, Habermas argumenta que nuestro fracaso a la hora de mantener debates públicos serios sobre la genética, y su lenta normalización e infiltración en la práctica médica rutinaria, tiene un impacto directo y pernicioso sobre nuestra autocomprensión como sujetos humanos y, como consecuencia, tendrá efectos adversos sobre el fundamento mismo de nuestra cultura política liberal. Por tanto, Habermas está interesado en desarrollar argumentos en contra de la eugenesia liberal, no sólo ni simplemente porque le interese el hipotético estatuto de los clones y las personas humanas genéticamente mejoradas, sino sobre todo porque nuestro fracaso a la hora de ocuparnos con seriedad de las implicaciones éticas y morales del uso de tecnologías genéticas sobre nosotros mismos alterará la naturaleza de nuestra cultura política liberal. Esta línea de argumentación no debería resultar sorprendente. Una de las afirmaciones centrales del trabajo de Habermas en filosofía política es que hay relación entre nuestras intuiciones morales, normas jurídicas y principios políticos. Es esta relación entre lo moral, lo jurídico y lo político lo que le permite a Habermas defender el carácter normativo de la política y su imbricación con los derechos que se recogen en las constituciones. Se podría incluso afirmar que Habermas ha acercado tanto la moralidad a la ley que de hecho las ha fundido. No obstante, del mismo modo que las normas jurídicas tienen un contenido normativo, también el estado liberal, constitucional y de derecho tiene una dimensión normativa. Por otra parte, hay un paralelismo entre ley, moralidad y liberalismo político, de tal modo que cada uno de ellos refleja de forma diferente ciertas intuiciones normativas básicas que pueden remontarse a la estructura misma de la interacción comunicativa. En la base de la interacción comunicativa, o en su núcleo, encontramos la autonomía de la persona dialógica y pensante, que expresa y vive su autonomía precisamente dando razones, y que tiene siempre la prerrogativa de decir «sí» o «no» ante los actos de habla de los demás. El sujeto moral autónomo está protegido por derechos, y esos derechos a su vez se mantienen gracias a agentes públicos que actúan de manera autónoma. Es este núcleo del liberalismo político, que remite a la autonomía moral básica pero también a la vulnerabilidad de la persona humana, lo que se ve amenazado por las perspectivas de la 
clonación y la mejora genética. En la medida en que la autonomía de las personas quede socavada por la autooptimización y autoinstrumentalización que la genética nos permite, nuestra modernidad política y moral se verá también amenazada.

Hemos de ser claros, a Habermas no le preocupa el estatuto legal de los seres humanos futuros que se «producirían» por medio de DGP o de mejoras genéticas ${ }^{5}$. Lo que le preocupa es la autocomprensión moral que podríamos estar expresando, aunque fuera en silencio, debido a nuestro consentimiento tácito en permitir que la eugenesia liberal se extienda sin control, y también le preocupa la autocomprensión moral que los porthumanos posclonales y eugenésicos del futuro tendrían de sí mismos. En cuanto a la primera cuestión, Habermas es consciente de que hay pocos argumentos convincentes que puedan presentarse a favor de la prohibición del DGP. Una vez más, la falta de argumentos en contra del DGP tiene que ver con nuestra incapacidad para proporcionar criterios claros para distinguir la eugenesia positiva de la negativa. Sin embargo, Habermas piensa que puede haber un camino para empezar a delinear criterios si pensamos en nuestros futuros hijos como las segundas personas en un diálogo sobre las intervenciones médicas que podrían aceptar. La sugerencia es que, en ausencia de criterios claros, deberíamos abstenernos en todos los casos de pensar en nuestros hijos como terceras personas, o como entidades a nuestra total disposición. Tratar a nuestros futuros hijos y a las generaciones venideras como terceras personas significa instrumentalizarlos por completo, y al hacer eso, no los estamos considerando miembros de nuestras comunidades morales, aunque sólo lo sean de forma virtual. Únicamente si tratamos a nuestros hijos o a las generaciones futuras como las segundas personas de un diálogo virtual, podremos comprobar si estarían de acuerdo con nuestras decisiones referentes al uso del DGP en su genotipo. En otras palabras, sólo si somos capaces de imaginar argumentos con los que nuestras generaciones futuras podrían hipotéticamente consentir en que modificáramos su genotipo sería aceptable que lo hiciéramos.

Considerar a las generaciones futuras como las segundas personas en un debate virtual o hipotético sobre lo que deberíamos o no deberíamos haber hecho con respecto a las intervenciones genéticas está ligado a nuestro modo particular de relación con otros miembros de la comunidad moral. Las generaciones futuras son parte de nuestra comunidad moral, aunque sólo como un futuro anterior, o como participantes virtuales. La clonación y la genética no son los únicos casos límite en los que la consideración de las generaciones futuras como interlocutores morales ha pasado a primer plano. Se puede incluso ir un paso más allá. Una de las virtudes de las moralidades posconvencionales

${ }^{5}$ De hecho, Habermas se ocupa de este tema en una serie de editoriales, publicados en Jürgen Habermas, La constelación posnacional. Ensayos políticos, trad. de P. Fabra, D. Gamper y L. Pérez, Barcelona, Paidós, 2000, pp. 207-217. En estos breves editoriales, Habermas utiliza el argumento de Hans Jonas sobre el derecho a un futuro abierto para rechazar la clonación. 
es que amplían la comunidad moral ante la que somos responsables no sólo horizontal y sincrónicamente, sino también vertical y asincrónicamente. Nos hemos vuelto responsables por el pasado tanto como por el futuro ${ }^{6}$. Somos responsables de lo que hicieron nuestros antecesores, pero también de lo que hacemos o dejamos de hacer, y de cómo afecta a las generaciones futuras. Somos responsables del futuro de nuestros actos de comisión y omisión. Lo importante aquí, no obstante, es que cuando nos relacionamos con miembros de nuestra comunidad moral, que no tiene fronteras e incluye a todos los interlocutores potenciales, presuponemos lo que Habermas denomina una «relación de simetría», que a su vez se relaciona con la dignidad humana (51). La dignidad humana es la denominación de la inviolabilidad que delimita las relaciones interpersonales. Allí donde hay una comunidad moral, hay una comunidad en la que el respeto mutuo se expresa en la idea de la inviolabilidad de cada persona. Pero esta inviolabilidad es sólo válida en la medida en que su asignación sea simétrica. Allí donde haya alguien que esté disponible para los intereses de otros, será violable, o mejor dicho, será un ser humano de usar y tirar; y allí donde esto ocurra, no habrá simetría relacional, sino una relacionalidad asimétrica o patológica. Lo que buscan las normas morales es proteger esta inviolabilidad ${ }^{7}$.

En la historia social de la humanidad, las normas morales emergen como mecanismos compensatorios para la neotonía o exogenia humana, es decir, el hecho de que el ser humano es inherentemente inacabado y prematuro. Los humanos, básicamente, nacen frágiles, incompletos $\mathrm{y}$, podríamos decir, mutilados y totalmente a merced de las inclemencias del mundo externo y de la generosidad o crueldad de los otros seres humanos. En palabras de Habermas, «La regulación normativa de las relaciones interpersonales puede entenderse como una envoltura protectora porosa contra las contingencias a las que se ven expuestos el cuerpo (Leib) vulnerable y la persona en él encarnada. Los ordenamientos morales son construcciones quebradizas que, ambas cosas

${ }^{6}$ Algo que ha argumentado magistralmente Reyes Mate en su libro La razón de los vencidos, Barcelona, Anthropos, 1991.

${ }^{7}$ Habermas ya expresó puntos de vista similares en su largo ensayo, «Remarks on Discourse Ethics», donde escribe: «la persona desarrolla una vida interna y logra una identidad estable sólo en la medida en que también se externalice a sí misma en relaciones interpersonales generadas por la comunicación, y se implique a sí misma en una red incluso más densa y diferenciada de vulnerabilidades recíprocas, de tal modo que se coloque en necesidad de protección. Desde este punto de vista antropológico, la moralidad puede concebirse como la institución de protección que compensa por la precariedad constitucional implícita en la forma misma de vida sociocultural. Las instituciones morales nos dicen cómo deberíamos comportarnos para compensar la vulnerabilidad extrema del individuo a través de la protección y la consideración. Nadie puede preservar su integridad por sí mismo. La integridad de las personas individuales requiere la estabilización de una red de relaciones simétricas de reconocimiento en las que individuos no sustituibles puede asegurar sus frágiles identidades de modo recíproco sólo como miembros de una comunidad». Véase Jürgen Habermas, Justification and Application: Remarks on Discourse Ethics, trad. de Ciaran P. Cronin, Cambridge, Mass, The MIT Press, 1993, p. 109. 
en una, protegen a la physis contra lesiones corporales y a la persona contra lesiones interiores o simbólicas» (51). La persona emerge como autónoma a través de las relaciones intersubjetivas, esto es, de la socialización. Nos socializamos en la autonomía al ir educándonos desde la total dependencia hasta la independencia, o independencia relativa. La autonomía, no obstante, sólo se estabiliza o logra la autoconciencia dentro del «entramado de unas relaciones de reconocimiento intactas» (51). La autonomía se logra en la culminación de un proceso de socialización que asume y sublima la fragilidad y neotonía física convirtiéndola en mutualidad y codependencia. Por esta razón, la autonomía siempre va acompañada de solidaridad, la independencia de empatía, la autodeterminación por dependencia declarada. Por esta razón, la dependencia, o el reconocimiento, que es la otra cara de la autonomía, explica «la vulnerabilidad del uno con respecto a los otros» (51). La autonomía, en este sentido, es un logro siempre inestable, que permite a los seres morales un alivio de su fragilidad corporal y su vulnerabilidad simbólica. Por esta razón, puede entenderse por qué es un logro la relacionalidad simétrica, el resultado de un proyecto de socialización y el resultado de un cuidado deliberativo. Cuando tratamos a los miembros de las generaciones futuras como segundas personas, los estamos tratando como miembros de nuestra comunidad de moralidad, aunque sólo sea hipotéticamente. Por esta razón, estamos obligados a tener en cuenta la integridad moral de los niños futuros. Cuando intervenimos en el genotipo de un futuro niño, estamos de hecho violando su integridad moral y corporal. Tenemos aquí, a grandes rasgos, un argumento posmetafísico y laico para rechazar la eugenesia liberal, que se extiende en las intuiciones fundamentales de la ética del discurso, y un enfoque teórico discursivo del liberalismo político, en el ámbito de las tecnologías de reproducción humana.

La propuesta de Habermas es sugerente, aunque quizá no convenza del todo. Ciertamente, no está claro si nuestras generaciones futuras estarían de acuerdo con nuestras decisiones de no permitir su mejora, privándoles así de oportunidades superiores de vida. Podrían estarnos tremendamente agradecidos por haberles ahorrado los efectos debilitadores de alguna enfermedad congénita. Pero también podrían estar resentidos con nosotros por no haberles permitido una esperanza de vida más larga, CIs más elevados, cuerpos más musculosos, etc. De hecho, el criterio discursivo, que requiere que consideremos un intercambio hipotético con las generaciones futuras, parece desplazar únicamente el locus temporal de nuestro dilema desde el presente al futuro. El dilema no se resuelve, porque ni siquiera las generaciones futuras van a saber si una intervención genética específica se ha llevado a cabo para curar o simplemente para mejorar. Pensemos en el siguiente ejemplo: las generaciones futuras también tendrán que enfrentarse al reto de tener que decidir si optimizar la salud de todos los miembros de la sociedad, disminuyendo los casos de, digamos, cáncer de mama y obesidad. En algunas ocasiones, ninguna de estas enfermedades es extremadamente debilitadora, aunque tenga impacto en las vidas 
de los individuos y en el gasto total de la sociedad en cuidados médicos. Se puede ir todavía un paso más allá, las generaciones futuras podrían estar sometidas a una mayor presión para maximizar la salud y aminorar la vulnerabilidad ante la enfermedad y la discapacidad, tanto por sus esperanzas de vida más largas como por la menor disponibilidad de recursos sociales y naturales. En otras palabras, las generaciones futuras podrían acusarnos, como nosotros acusamos a nuestros padres y a las generaciones precedentes, por no haber tenido suficientemente en cuenta las necesidades de las generaciones venideras.

No es necesario convertirse en posmoderno, ni tragar toda la palabrería apocalíptica de los poshumanistas, para reconocer que la enfermedad y la salud, lo patológico y lo normal, están en función de convenciones culturales. Si pensamos en la salud como el silencio del cuerpo, citando a Canguilhem, entonces tendremos que preguntarnos qué cuenta como ese silencio. Obviamente, ese silencio sería algo así como no estar limitados por nuestros cuerpos para desarrollar un proyecto de vida satisfactorio que pudiera otorgar a nuestra existencia un contenido, una coherencia, una narrativa que nos permitiera decir que hemos vivido nuestras vidas bien, vidas que no han sido desperdiciadas o estropeadas. Sin embargo, ¿no significa también este silencio, quizás, no morir demasiado joven, no perder nuestro cabello demasiado pronto, no sufrir fuertes y debilitadores síndromes premenstruales, no ser capaces de concentrarnos lo suficiente como para seguir tanto la lógica de un programa informático como las ecuaciones diferenciales de un problema de física? Por el momento, una cosa es cierta: que no sabemos si la nueva genética mejorará la autonomía de los sujetos, o si esta mejora de la humanidad alterará irreversiblemente nuestra autocomprensión como personas morales. Desde el punto de vista de Habermas, sin embargo, tenemos una barandilla a la que podemos aferrarnos y que nos guía en las proximidades de este abismo moral, la que proporciona una ética de la especie (Gattungsethik).

Entiendo que cuando Habermas habla de la ética de la especie quiere decir que todos, en tanto seres humanos vivos, compartimos ciertos compromisos fundamentales respecto a la conservación de la especie y la vida en consonancia con el «ser de la especie» propio de los seres humanos. Por razones obvias, Habermas no utiliza el término «ser de la especie». Sin embargo, este término puede ayudarnos a dar nombre a dos aspectos del ser humano que Habermas cree que son el punto de partida de cualquier concepción de lo que significa ser un miembro de la especie. El primero tiene que ver con el hecho de que, en tanto humanos, tenemos un cuerpo que nace, no se hace. En otras palabras, la naturaleza nos dota de un cuerpo, pero este cuerpo ni nos lo dan otros ni nos lo damos a nosotros mismos. Este cuerpo es una naturaleza interna, el que nos otorga nuestra condición humana. En yuxtaposición, existe un cuerpo social, que viene a constituir nuestra segunda naturaleza, y que viene dado por el mundo cultural. Ser un ser humano vivo es tener dos cuerpos: un cuerpo que nace y se sufre, y un cuerpo que nos es 
dado o que nos damos a nosotros mismos, contra el que luchamos pero que también puede reinscribirse y negociarse. Ser humano es asumir el reto de la contingencia de nuestra naturaleza corporal, dándose cuenta de que es un hecho contra el que tenemos que luchar, y al que tenemos que adaptarnos. El segundo aspecto tiene que ver con que, en tanto seres humanos vivos, somos un cuerpo y tenemos un cuerpo (la distinción entre Korpersein y Korperhaben que Habermas toma de Helmunt Plessner (72). El dasein del ser humano es tal que no puede existir sin un cuerpo, esto es, tal que su identidad está entrelazada con su cuerpo. Sin embargo, también tenemos un cuerpo, de tal modo que podemos imaginarnos a nosotros mismos en otro cuerpo. Tenemos una relación dual con nuestro cuerpo: no podemos ser sin él, pero nuestro dasein no se agota en él. La biotecnología, las modificaciones genéticas de nuestro genotipo y el DGP implican para Habermas una disrupción de este «ser de la especie», de la corporalidad simultáneamente contingente e ineludible del ser humano. Una ética de la especie exige respeto, o consideración, hacia cómo nuestras identidades morales están ligadas a lo que podemos aquí denominar el «estar arrojado en el mundo» [detrope y Geworfenheit] de la corporalidad humana. Ser un ser humano vivo significa llegar a ser consciente y lograr cierta autonomía moral partiendo del hecho ineludible de la lotería genética que nos otorga a cada uno nuestro cuerpo.

Sin duda alguna, habrá quien se oponga a este enfoque teórico discursivo respecto a los desafíos que implica la genómica. De hecho, es de esperar que haya disenso y desacuerdo, algo que ya es una característica permanente de nuestras sociedades modernas, como Habermas reconoce de forma explícita. El liberalismo político de tipo deliberativo y constitucional como el que defiende Habermas es precisamente deseable porque no sólo busca proteger diferencias en perspectivas éticas al mismo tiempo que mantiene el compromiso con algunas normas morales básicas, como la norma moral según la cual todos los pares morales deben ser tratados como iguales. La ética del discurso armoniza con la democracia deliberativa porque juntas mantienen el compromiso con el universalismo moral junto al respeto declarado por la prerrogativa individual de escoger un plan de vida coherente y con significado. La ética deontológica y el liberalismo político procedimental aparecen como los epítomes de la modernidad porque recogen tanto el universalismo como la atención a la singularidad del individuo. Como ya se anticipó antes, la autonomía es la otra cara de la dependencia reconocida. Alternativamente, la autonomía es el resultado de una relacionalidad simétrica consciente de la necesidad de relaciones de reconocimiento mutuo saludables, es decir, no coercitivas y no estratégicas. Pero, ¿cómo podemos convencer a alguien para que acepte la propuesta de la ética del discurso sin estar asumiendo al mismo tiempo las presuposiciones de la ética del discurso? Y aquí Habermas introduce el argumento de que el compromiso con la perspectiva moral es el resultado de un compromiso ético previo. Citando a Habermas: «Bajo las condiciones del pensamiento pos- 
metafísico, de una autocomprensión ética de la especie inscrita en determinadas tradiciones y formas de vida, no se pueden concluir argumentos que desbanquen las pretensiones de validez de una moral presuntamente válida para la generalidad. Pero esta "prioridad de lo justo frente a lo bueno" no puede impedir ver que la moral racional abstracta de los sujetos a derechos humanos se apoya a su vez en una autocomprensión ética de la especie preexistente, compartida por todas las personas morales» (59). En otras palabras, las tradiciones éticas y locales que proyectan autocomprensiones éticas específicas no pueden anular o triunfar sobre las afirmaciones de la perspectiva moral universalista que ha sido recientemente recogida en la declaración universal de los derechos humanos. Sin embargo, y simultáneamente, este mismo efecto de desubicación y disociación que la modernidad tiene sobre las tradiciones éticas está sostenido y respaldado por una comprensión ética, a saber, una idea ética que asigna un contenido ético específico a la idea misma de sujeto moral. El universalismo moral es en sí mismo un valor ético, un valor sustantivo que asigna a los seres humanos cualidades y propiedades particulares que no son simplemente formales, sino sustantivas. Tratar a alguien como miembro de la comunidad moral requiere que se respete su integridad corporal y personal, de otro modo no existiría una comunidad moral.

\section{II. ¿Necesitamos realmente una ética de la especie para detener nuestra vertiginosa caída?}

El futuro de la naturaleza humana. ¿Hacia una eugenesia liberal? es ciertamente el Habermas clásico, es decir, el mejor Habermas ejerciendo de filósofo al servicio del público. Ha intervenido con una propuesta muy sugerente y realmente informativa acerca de cómo reencuadrar los asuntos de la clonación y las modificaciones genéticas de los seres humanos. En el proceso, además, ha refinado su definición de ética del discurso y extendido sus ideas sobre la autonomía moral en la dirección de la fragilidad corporal. Se trata de aclaraciones y adiciones muy importantes para una teoría moral que está ganando fundamento y seguidores. Sin embargo, identifico una serie de presuposiciones inquietantes que ponen en peligro las ganancias en otros terrenos, y, lo que es más importante, esas defectuosas y muy discutibles presuposiciones podrían sugerir un giro metateórico que pone en tela de juicio el carácter posmetafísico de la pragmática universal y la teoría de la acción comunicativa, con sus propuestas subsidiarias de una teoría del estado y una ética del discurso.

El principal y más obvio de los problemas que presenta la argumentación desarrollada por Habermas es que parece funcionar en el marco de un determinismo genético implícito pero fácilmente identificable. El determinismo genético es ideología, no ciencia. Ya existe evidencia suficiente para demostrar que un organismo vivo no se puede reducir a su código genético. De hecho, el código genético funciona como una molécula decodificadora de otros procesos 
bioquímicos más importantes. El código genético de un organismo vivo es sólo una parte de un complejo sistema bioquímico en el que el ambiente y un nivel secundario de replicación de proteínas tienen un papel igualmente importante, si no más. Por esta razón, el mundialmente famoso Richard Lewontin, Profesor de Investigación Alexander Agassiz en el Museo de Zoología Comparada de la Universidad de Harvard, ha acuñado el término triple hélice para subrayar que no son los genes los que determinan a los organismos vivos, sino que es la interacción entre gen, organismo y ambiente lo que da lugar a un ser vivo único ${ }^{8}$. El genotipo, el fenotipo y lo que podríamos llamar proteotipo componen la matriz que sostiene la vida de los organismos ${ }^{9}$. Desde el punto de vista de la evolución de proteínas y moléculas, las proteínas son previas al ADN, y algunos arqueólogos de los genes especulan que el ADN está al servicio de las proteínas, como una especie de banco de recuerdos. El determinismo genético ha invertido este orden de prioridad: las proteínas están al servicio del ADN, el fenotipo y el proteotipo están al servicio del genotipo. Es está red de interdependencia entre tres áreas en interacción muy variable e inestable la que explica el hecho de que los gemelos genéticos puedan terminar siendo tan diferentes. Como Barry Commoner expresa en un artículo reciente: «El ADN no creó la vida; la vida creó el ADN. Cuando la vida surgió sobre la tierra, las proteínas debieron aparecer antes del ADN porque, a diferencia del $\mathrm{ADN}$, las proteínas tienen la habilidad catalítica de generar la energía química necesaria para reunir pequeñas moléculas ambientales en otras más grandes como las de $\mathrm{ADN}$. El $\mathrm{ADN}$ es un mecanismo creado por la célula para almacenar la información que ella misma produce» ${ }^{10}$. El determinismo genético es el darwinismo social del siglo xx, y también una pseudociencia inaceptable.

Concedamos, no obstante, que Habermas no está presuponiendo ninguna forma de determinismo genético; que, de hecho, acepta todas las críticas científicas a esta ideología descarada, ise sostienen en ese caso el resto de sus argumentos? Creo que la mayor parte de los argumentos de Habermas aún se sostendrían y serían válidos incluso si elimináramos su determinismo genético encubierto. Me ocuparé ahora de las elaboraciones de Habermas de una ética de la especie. Considero que su intuición es profundamente noble, y simpatizo

${ }^{8}$ Richard C. Lewontin, The Triple Helix: Gene, Organism, and Environment, Cambridge, Mass, Havard University Press, 2000, y también El sueño del genoma humano y otras ilusiones, trad. de R. Ibero, Barcelona, Paidós, 2001.

${ }^{9}$ El estudio del genoma se denomina «genómica». El estudio del proteotipo se denomina «proteómica». A la estela de la cartografía del genoma humano y del inesperado descubrimiento de que el genoma humano tiene tantos genes como una semilla de mostaza, la proteómica ha surgido como la nueva frontera genética. Véanse los artículos publicados en Scientific American, abril 2002, y Karen Hopkin, «Proteomics: The Post-Genome Project», en Scientific American, vol. 265, núm. 2, agosto 2001, p. 16. Véase también Carol Ezzell, «Proteins Rule», Scientific American, vol. 286, núm. 4, abril 2002, pp. 40-47.

${ }^{10}$ Barry Commoner, «Unraveling the DNA Myth: The Spurious Foundation of Genetic Engineering», en Harper's Magazine, vol. 304, núm. 1821, febrero 2002, pp. 39-47, cita de la p. 47. 
mucho con ella. No obstante, fundamentar una ética de la especie sobre las nociones duales del determinismo biológico, así como sobre la distinción entre lo que nos es dado por la naturaleza y lo que nos damos a nosotros mismos a través de la tecnología, es asumir que debemos aceptar la lotería genética como un hecho de la vida y que la tecnología sólo ha pretendido manipular y transformar la naturaleza. Nos encontramos aquí con dos presuposiciones muy cuestionables: la primera, que si queremos intervenir sobre nuestros cuerpos para hacerlos menos «arbitrarios», nos estaremos convirtiendo en nuestra propia creación; y la segunda, que estaremos traicionando nuestra naturaleza humana si intentamos transformar lo que nace en lo que se hace. Estas dos presuposiciones pueden reducirse a una distinción esencial, entre la naturaleza interna y externa, entre lo biológico y lo cultural, entre lo que nace y lo que se hace, entre lo que se crea y lo que se inventa. Se trata de una distinción crucial porque sobre ella descansan importantes cuestiones relacionadas, por ejemplo, con nuestra habilidad para otorgar patentes sobre organismos genéticamente modificados que, realmente, no se han inventado ni fabricado, sino que son una remezcla de material genómico ya existente de forma natural. No obstante, me gustaría argumentar que la distinción entre lo natural y lo creado, entre la naturaleza interna y externa, es cultural y no ontológica, y va alternando auge y decadencia al compás tanto de los cambios tecnológicos y científicos como de los cambios conceptuales o de Weltanschaungen. En otras palabras, lo que se toma como naturaleza «interna», o lo que nace, es aquello que la tecnología ha acordonado como intocable. Lo biológico en el sentido que Habermas sugiere es aquello de lo que podemos decir que la tecnología no debería tocar; pero al mismo tiempo que hacemos este pronunciamiento, ya sabemos y aceptamos que la tecnología lo ha contaminado. Otra forma de decirlo sería preguntar: ¿hasta qué punto es el homo sapiens de hoy resultado de la naturaleza y producto de la tecnología ( $i$. e., de la tecnología, la ciencia y la intervención deliberada en su naturaleza a través de medios culturales)? ¿Podríamos argumentar junto con Engels que la mano ha evolucionado debido a la invención de la herramienta, y que la invención de la agricultura y el uso del fuego nos han convertido en los animales que somos hoy? Los cerdos, las vacas y los caballos existen en la naturaleza, cierto, pero no como los que hemos domesticado, criado, seleccionado y diseñado. De hecho, podríamos argumentar que las vacas y los caballos que conocemos no son como los que podríamos encontrar en la naturaleza, y que, en un sentido estricto, son antinaturales, creados más bien que encontrados o descubiertos ${ }^{11}$. Algún día, de hecho, después de que un meteorito o una bomba atómica dejara este planeta

${ }^{11}$ Las vacas, los cerdos y los caballos son muy similares a los perros. De hecho, y como apunta Donna Haraway, esas criaturas ocupan un lugar único en la ontología de los organismos vivos, porque son ni/ni, en vez de tanto/como. Haraway señala en una entrevista: «... los perros [y aquí yo añadiría vacas, caballos y cerdos] tiene un gran muestrario de ontologías posibles cuya esencia es la relación, y muy especialmente las relaciones con los humanos en formas históricas diversas... Me interesa el hecho de que los perros no son nosotros. Así que representan no-nosotros. 
inmerso en una oscura edad de hielo, el planeta se acabaría repoblando con las plantas y animales que nosotros criamos, creamos y sintetizamos a través de los siglos, y algunos poshumanoides del futuro los llamarían «naturaleza» ${ }^{12}$. Sigue siendo un hecho que nos hemos creado a nosotros mismos en el proceso de domesticar a la naturaleza, y en este proceso de domesticar a la naturaleza hemos transformado nuestra propia naturaleza. La domesticación de la naturaleza ha sido la domesticación de nuestra propia naturaleza; la humanización de la naturaleza ha sido la desnaturalización de la humanidad. Es esta maleabilidad, y la incesante intervención en nuestras naturalezas, lo que se ha resumido en una doctrina central de la tradición judeocristiana, una tradición que da forma al romanticismo de la ilustración y de las revoluciones francesa y americana, y que también da forma a la invención de las ciencias sociales que impulsan una parte tan importante de la ingeniería social y el meliorismo. Me estoy refiriendo a la doctrina del imago Dei, a saber, que la humanidad ha sido creada a imagen y semejanza de Dios ${ }^{13}$. Fue Giovanni Pico della Mirandola quien ofreció la articulación más sucinta y elocuente de esta doctrina esencial cuando dijo que los humanos son como Dios porque no tienen lugar en el orden natural, y porque son, como Dios, creadores, pero creadores no sólo de cosas en el mundo, sino también de sí mismos. Como Dios, además, los humanos son iniciadores de lo nuevo, introducen novedad en el cosmos en tanto que creadores ${ }^{14}$. Es esta última versión de la doctrina del imago Dei la que encontramos reflejada en el concepto de natalidad de Hannah Arendt, una noción a la que Habermas apela en este texto, aunque con otros objetivos en mente ${ }^{15}$. Sea como sea, hay una profunda ambivalencia en esta doctrina

No son simplemente lindas proyecciones. Los perros no representan espejos-para-mí. Los perros representan otra especie, pero otra especie con la que vivimos en íntima relación, otra especie para la que la división naturaleza/cultura es más un problema que una ayuda cuando tratamos de entenderla. Porque los perros no son ni naturaleza ni cultura, no son tanto/como, ni siquiera ni/ni, sino otra cosa distinta» (Entrevista con Donna Haraway, en prensa). Gran parte del trabajo de Haraway trata de esta «otra cosa» para la que a veces usa el término «cyborg». Véase el breve pero excelente panorama de su trabajo en George Myerson, Donna Haraway and GM Foods, Cambridge, UK, Icon Books Ltd., 2000.

${ }^{12}$ Éste es el mensaje conmovedor y profundamente desasosegante que Steven Spielberg lanza en su película IA, del año 2001. El pequeño androide construido como un hijo sucedáneo, que luego es abandonado por su madre, es resucitado después de milenios hibernando en el fondo de los mares helados de la tierra por una raza alienígena del futuro. En los recuerdos de su cerebro positrónico, la humanidad sigue viviendo. Nuestras creaciones nos recuerdan. Nuestras invenciones se convierten en nuestro pasaporte para la inmortalidad.

${ }^{13}$ Véase Gerhart B. Ladner, The Idea of Reform: Its Impact on Christian Thought and Action in the Age of the Fathers, Nueva York, Harper Torchbooks, 1967.

${ }^{14}$ Giovanni Pico della Mirandola, Discurso sobre la dignidad del hombre, ed. lit. de P. Quetglas, Barcelona, PPU, 1988.

${ }^{15}$ Véase Hannah Arendt, La vida del espíritu, trad. de R. Montoro y F. Vallespín, Madrid, Centro de Estudios Constitucionales, 1984, especialmente la discusión en la segunda parte, sobre Voluntad, donde Arendt liga de forma explícita la discusión sobre el imago Dei a la natalidad. Véase también su tesis doctoral El concepto de amor en San Agustín, trad. de A. Serrano, Madrid, 
que se introduce en el génesis. Tenemos que ser como Dios, pero nunca debemos sobrepasarle. Sin embargo, el imperativo está ahí: cuidar, atender, trabajar duro y transformar, pero también crear. ¿No es entonces una ética de la especie, en esta tradición, una ética del imperativo de la autocreación y la autotransformación?

Sin duda, éste es sólo un aspecto de los argumentos de Habermas contra el DGP y las autooptimizaciones genéticas. Los otros tienen que ver con la autocomprensión moral de las generaciones futuras. Estos argumentos pueden resumirse en dos líneas principales. Una afirma que las personas modificadas y reconstruidas por medio de la ingeniería genética no se verán a sí mismas como autoras de sus historias vitales. La otra, que no se considerarán como iguales respecto a otras generaciones porque habríamos socavado su autonomía al apropiarnos de sus futuros a través de nuestras intervenciones genéticas.

Respecto a la primera objeción, podríamos decir que el rechazo del determinismo genético sería suficiente para evitar esta preocupación. En otras palabras, incluso cuando interviniéramos y cribáramos genéticamente a las generaciones futuras, no estarían más determinados de lo que nosotros hemos estado. No hay asimetría entre nosotros y ellos porque ellos hayan sido cribados y nosotros no. Las personas sometidas a ingeniería genética tienen que enfrentarse al «estar arrojado en el mundo» que caracteriza su existencia tanto como la nuestra. Un clon no es menos responsable de su historia vital que nosotros. Una historia vital nunca está determinada por un genotipo, ya que éste lo único que hace es proporcionar el material, por así decirlo, a partir del que nosotros construimos el sentido de nuestros planes de vida. Expresándolo en la lacónica frase pronunciada por el personaje de Ethan Hawk en la película de 1997 GATTACA: «el gen del destino no existe» —aunque, yo añadiría, y quizá más correctamente, «el gen de la libertad humana no existe»- Habermas asimila con demasiada rapidez la manipulación del genotipo con la determinación de la historia vital porque también parece pensar que hay correspondencia o simetría entre los cuerpos y sus historias vitales. Aunque sus elucidaciones sobre la interdependencia entre la integridad corporal y el reconocimiento simbólico para la autonomía moral son bienvenidas, esto no implica ipso facto que seamos nuestros cuerpos. El viejo misterio filosófico de la relación que tenemos con nuestros cuerpos no se resolverá ni con ingeniería genética ni con las elucubraciones cyberpunk sobre mentes que pueden descargarse en discos duros ${ }^{16}$. Un clon, o un humano genéticamente modificado, no será su cuerpo más de lo que nosotros somos nuestros cuerpos dados por la natu-

Encuentro, 2001. La discusión de la natalidad en La condición humana, trad. de R. Gil, Barcelona, Paidós, 1998, relaciona la historia del génesis, de donde emerge la doctrina del imago Dei, con la discusión sobre la pluralidad, así como con la cuestión de los orígenes y la natalidad.

${ }^{16}$ Véase el maravilloso ensayo de Carol Rovane, «Genetics and Personal Identity», en Justine Burley y John Harris (eds.), A Companion to Genethics, Malden, MA, Blackwell Publishers, 2002, pp. 245-252. Sobre las tecnofantasías de descargar mentes en ordenadores, véase Ray Kurzweil, The Age of Spiritual Machines, Nueva York, Viking, 1999. Véanse también las historias breves 
raleza. De un modo análogo, sus historias vitales son igualmente suyas para desperdiciar o para convertir en ejemplares. De hecho, el argumento de Habermas es tan antiintuitivo que me hace pensar si he pasado por alto el argumento real. Porque, enfrentados a una vida para vivir, un clon o un humano genéticamente modificado no serán menos responsables, o irresponsables, que cualquiera de nosotros, genéticamente en bruto o no-válidos para utilizar de nuevo la terminología introducida en la película de Andrew Niccols, GATTACA, a no ser, por supuesto, que estemos pensando en sus vidas enteras como escritas en su código genético, una presuposición inaceptable.

El segundo argumento es aún más indefendible. Hay, y continuará habiendo, asimetrías generacionales. Y a pesar de las veces que hemos caído en esa especie de autoengaño de decir que hemos nacido en el lugar equivocado y en el momento inoportuno, siempre somos hijos de nuestro tiempo. Nosotros, hoy, en el amanecer del siglo XXI, estamos en profunda asimetría respecto a las generaciones anteriores, una asimetría que es mayor aún respecto a las generaciones previas a ellas, y sin punto de comparación con veinte generaciones atrás. Consideremos los personajes de ficción de las narraciones breves de Berhard Schlink, que se debaten con los conflictos de cómo relacionarse con sus padres, y sus abuelos, y su cooperación, consciente o inconsciente, con los nazis ${ }^{17}$. Las generaciones posteriores a los años 60 podrían afirmar que tienen una relación asimétrica con sus generaciones precedentes, y podrían sentirse resentidos e incluso despreciar a sus padres por lo que no hicieron, o por lo que hicieron que no deberían haber hecho. Imaginemos a un joven estadounidense tratando de aceptar la participación de sus padres y de sus abuelos y de sus bisabuelos en la esclavitud, «Jim Crow» ${ }^{18}$, o el bombardeo de Hiroshima y Nagasaki. Estas generaciones más jóvenes, y las generaciones futuras, siempre sufrirán la dolorosa consciencia de la asimetría que los separa de las generaciones pasadas y, por supuesto, también de las futuras. ¿Puede el cribado y la optimización genética de las generaciones futuras crear una cesura entre generaciones más profunda que la creada por Auschwitz, los Gulags e Hiroshima? ¿No es cierto que estamos siempre hipotecando el futuro de las generaciones futuras, perpetuando así la asimetría entre generaciones?

Estas objeciones todavía no llegan a lo que creo que es el núcleo de la preocupación de Habermas en este vigoroso argumento laico en contra del

de Greg Egan, especialmente «Closer», recogidas en su libro, Axiomatic, Nueva York, Harperprism, 1997, pp. 261-276, para una de las exploraciones de ciencia ficción más sofisticadas desde el punto de vista filosófico sobre las implicaciones que la ingeniería genética y la simulación por ordenador tienen para la identidad personal.

${ }^{17}$ Véase Berhard Schlink, Flights of Love, Nueva York, Pantheon, 2001, y The Reader, Nueva York, Vintage Books, 1995.

${ }_{18}$ «Jim Crow», nombre con el que designaba despectivamente a la población negra en Estados Unidos, se utiliza también para hacer referencia a las leyes y costumbres de segregación racial, acompañadas de actos de violencia, que se imponen con especial gravedad a partir de 1890 en lo que se conoce como «era Jim Crow» [N. de la T.]. 
intervencionismo genético, a saber, una defensa de la modernidad política: «... el intento de prevenir por medios jurídicos que nos acostumbremos subrepticiamente a una eugenesia liberal y de asegurar que el engendramiento, esto es, la mezcla de las secuencias cromosómicas paternas, mantenga una cierta medida de contingencia o naturalidad, no sería expresión de ninguna imprecisa resistencia antimoderna. Sería más bien un acto político de acción moral autorreferente para garantizar la existencia de unas condiciones de conservación de la autocomprensión práctica de la modernidad. Tal interpretación se ajusta más, claro está, a la imagen sociológica de la modernidad que se ha hecho reflexiva» (41). En otras palabras, lo que está en juego en nuestra alegre aceptación de la eugenesia liberal es la naturaleza misma de la modernidad. Porque, como ya hemos visto, ponernos a disposición de nosotros mismos altera fundamentalmente nuestra autocomprensión moral de formas que Habermas piensa que socavan, si no destruyen, los fundamentos mismos de la modernidad política. A la luz de esto, el rechazo de la eugenesia liberal por medios jurídicos (i. e., legislación) se convierte en un «acto político» que busca conservar la estructura de la modernidad política. La preocupación es ciertamente legítima, y no deberíamos despreciar las inquietudes de Habermas. Sin embargo, hay muchas maneras de abogar por una respuesta a la clonación que no son necesariamente traiciones a la modernidad política. Es posible imaginar respuestas que de hecho hacen una virtud de la modernidad política y que podrían en la práctica terminar recomendando algo así como la criba y manipulación genética deliberativas. Presentaré dos argumentos que pueden entenderse como ejemplos del tipo de modernidad reflexiva que Habermas alaba, y que, no obstante, terminan en el lado contrario del campo de juego.

Para ser breve, vayamos directamente a un principio que ha desarrollado Peter Singer en un artículo reciente titulado. «Shopping at the Genetic Supermarket» [«De compras en el supermercado genético»] ${ }^{19}$. El principio reza así:

Para cualquier enfermedad $\mathrm{X}$, en caso de que si los padres infligieran $\mathrm{X}$ sobre sus hijos nada más nacer se considerara una forma de abuso infantil, entonces debería al menos permitirse (permaneciendo el resto de variables inalteradas) tomar medidas para prevenir que el hijo tenga esa enfermedad (6).

Peter Singer lo denomina el «principio preventivo», y con él Singer formaliza intuiciones que todos compartimos, tanto si somos padres como si no, a saber, la intuición de que estamos obligados a prevenir el daño tanto para nuestros hijos como para los de los demás, especialmente si este daño puede resultar en minusvalías y deshumanización. Este principio preventivo, además, «dice simplemente que el diagnóstico prenatal y las interrupciones selectivas [abortos] son permisibles si representan un modo de evitar una enfermedad que se con-

${ }^{19}$ Peter Singer, «Shopping at the Genetic Supermarket» (conferencia impartida en Stanford University, otoño 2001). Ver en este mismo volumen pp. 29-30. 
sideraría abuso infantil infligir sobre un hijo» (7). De hecho, los padres son responsables en caso de que se produzcan negligencias y abusos infantiles. Esta intuición moral se ha traducido, efectivamente, en legislación, y en un catálogo de derechos; derechos a los que podemos apelar cuando se producen casos de notorios errores médicos, o de simple negligencia médica. Las responsabilidades que los padres deben asumir respecto al bienestar de sus hijos se han ampliado con el aumento de nuestros conocimientos sobre peligros potenciales y riesgos inminentes. A su vez, nuestros sistemas jurídicos se han desarrollado y se han vuelto más detallados y explícitos sobre nuestras obligaciones, precisamente para dar representación legal a nuestra creciente responsabilidad moral. Muchos lamentan esta legalización de nuestro mundo moral, pero, ciertamente, Habermas no es uno de ellos. Sin embargo, me gustaría llevar el argumento de Singer un paso más allá combinándolo con algunas intuiciones del propio Habermas.

Los deberes negativos, del tipo «no hay que matar; no hay que causar dolor; no hay que evitar que alguien desarrolle sus habilidades, etc.» son deberes «que tienen como contenido la protección de la integridad de la persona como ser que actúa libremente» ${ }^{20}$. Estos deberes negativos, que están siempre acompañados de los derechos positivos, expresan intuiciones centrales de la tradición liberal: «la integridad de la persona parece estar adecuadamente protegida sólo por los deberes generales, incondicionales y negativos que aseguran las mismas zonas de inviolabilidad de la libertad subjetiva para todo el mundo imponiendo la obligación de abstenerse de ciertas acciones» ${ }^{21}$. Habermas reconoce esta tradición, pero va más allá, porque se expresa en el concepto monológico e individualista de sujeto moral y jurídico. Desde el punto de vista de Habermas, la rearticulación intersubjetiva y comunicativa de los deberes es lo que hace justicia a las intuiciones centrales del liberalismo. «A estos deberes centrales pertenecen únicamente aquellos que pueden entenderse como aspectos de la demanda general: "actúa orientado por la comprensión mutua y permite que todo el mundo tenga la libertad comunicativa necesaria para tomar partido sobre afirmaciones de validez"» ${ }^{22}$. Estos deberes son «fundamentales porque están orientadas a respetar la integridad de sujetos comunicativamente actuantes. Pero estas normas no tienen únicamente la fuerza de las obligaciones puramente negativas. Al comportarme honestamente no me abstengo simplemente del engaño, sino que al mismo tiempo realizo un acto sin el cual colapsaría la relación interpersonal entre participantes activamente involucrados en interacción que depende del reconocimiento mutuo. Las normas que prescriben como un deber la satisfacción de las presuposiciones pragmáticas necesarias de la acción comunicativa presentan una extraña indi-

${ }^{20}$ Jürgen Habermas, Justification and Application: Remarks on Discourse Ethics, trad. de Ciaran P. Cronin, Cambridge, Mass, The MIT Press, 1993, p. 65.

${ }^{21}$ Ibid., p. 66.

${ }^{22}$ Ibid., p. 66. 
ferencia respecto a la distinción entre deberes negativos y positivos: al mostrar respeto por otra persona, al mismo tiempo protejo el núcleo vulnerable de esa persona» ${ }^{23}$. Por esta razón, los deberes negativos también se formulan al mismo tiempo en términos positivos. Los deberes fundamentales de la interacción moral están directamente ligados a la conservación de la integridad simbólica y corporal de los agentes morales. Así, me gustaría afirmar que si tomamos el «principio preventivo» de Singer, que no hace otra cosa que formalizar intuiciones fundamentales sobre nuestros deberes de no permitir que otros seres humanos sufran, y lo traducimos al lenguaje habermasiano de la libertad comunicativa y la vulnerabilidad psíquica y simbólica, terminaremos llegando al deber de asegurar el bienestar de otros seres humanos. En otras palabras, no sólo se nos permite al menos prevenir que otros seres humanos sufran, sino que estamos obligados a buscar el bienestar de los otros, especialmente si ese bienestar está en nuestras manos. Este argumento también se aplica a nuestro deber con las generaciones futuras y, de este modo, podemos decir que la flecha del tiempo apunta en la dirección del futuro. Pero iqué ocurre con el argumento de que las generaciones futuras podrían tener algo que decir sobre lo que hemos hecho o no hemos hecho por ellos?

Siempre habrá una asimetría entre generaciones, como ya hemos observado, pero icuáles son nuestros deberes para con las generaciones futuras? Apelo aquí a la idea de justicia de Rawls, y a su elucidación de esa idea de justicia haciendo referencia a dos principios: el principio del «derecho igual al esquema más extenso de libertades básicas iguales que sea compatible con un esquema semejante de libertades para los demás» y el principio de que las desigualdades «sociales y económicas, habrán de ser conformadas de modo tal que a la vez que: $a$ ) se espere razonablemente que sean ventajosas para todos, $b$ ) se vinculen a empleos y cargos asequibles para todos» ${ }^{24}$. De momento, me centraré en la fascinante lectura que Rawls hace del principio de la diferencia respecto al tema que nos ocupa, i. e., cómo verían las generaciones futuras las modificaciones genéticas y el DGP. Citaré a Rawls, dado que es innecesario interpretarlo o muy difícil entenderlo mal:

Un sistema de castas, por ejemplo, tiende a dividir a la sociedad en poblaciones biológicamente separadas, en tanto que una sociedad abierta favorece la más amplia variedad genética. Por lo demás, es posible adoptar políticas eugenéticas de modo más o menos explícito. No me ocuparé de las cuestiones de la eugenesia, y me limitaré solamente a las preocupaciones tradicionales de la justicia social. A pesar de ello, debemos notar que, en general, el proponer políticas que reducen las capacidades de otros, no constituye una ventaja para los menos afortunados sino que, al aceptar el principio de diferencia, verán a las mayores capacidades como un capital social que habrá de usarse para beneficio común. No obstante, el tener mayores dones naturales estará

${ }^{23}$ Ibid., p. 66-67.

${ }^{24}$ John Rawls, Teoría de la justicia, trad. de M. D. González, México, FCE, 1979, § 11, p. 82 (cursivas añadidas). 
también en el interés de cada uno. Esto le ayudará a llevar a cabo su plan de vida preferido. Por tanto, en la posición original, las partes querrán asegurar para sus descendientes la mejor dotación genética (suponiendo que las suyas son fijas). La ejecución de políticas razonables a este respecto es algo que las generaciones posteriores deben a las anteriores, por lo que se trata de una cuestión entre generaciones ${ }^{25}$.

Gregory Pence comenta esto de la siguiente manera:

Rawls proporciona un marco para una respuesta coherente al argumento de que no deberíamos intentar mejorar la raza humana: si estuviéramos en el contrato social - tomando la perspectiva de millones de personas a través de muchas generacionesy no supiéramos en qué generación íbamos a vivir cuando se levantara el velo, escogeríamos que las generaciones más tardías tuvieran el mayor talento genético posible, haciendo esto compatible con la libertad individual e igualitaria para procrear en las generaciones precedentes ${ }^{26}$.

Así, no sólo no tenemos el deber negativo de no infligir sufrimiento, o de evitar enfermedades que puedan hacer que alguien sufra, sino que tenemos también el deber adicional de procurar el bienestar de nuestros pares morales. Si tenemos el deber de prevenir un daño que pueda definirse como abuso infantil, entonces tenemos el deber de procurar el bienestar de nuestros hijos de tal modo que les evitemos enfrentarse a enfermedades con las que no podrían desarrollar sus proyectos de vida. Al mismo tiempo, si entendemos la justicia como imparcialidad, una imparcialidad que se circunscribe por la maximización de las libertades de todos, y la tolerancia de las desigualdades sólo si benefician a todos en general, entonces también estamos obligados a tratar de mejorar las posibilidades de vida de las generaciones futuras. Ambas ideas nos permiten concluir que podemos aceptar, y deberíamos incluso defender tanto el DGP como algunas formas de optimización genética. Ya no se trata, entonces, de prohibir legalmente la eugenesia liberal, sino más bien de buscar el desarrollo de políticas y de legislación que permitan el acceso igualitario a los beneficios de las tecnologías genómicas. Y buscar desarrollar estas políticas no es una mera capitulación a hechos consumados de carácter comercial, médico y científico, sino más bien el acto político jurídicamente sancionado de una conciencia moral autorreferencial moderna y posconvencional.

${ }^{25}$ Ibid., § 17, pp. $130-131$.

${ }^{26}$ Gregory E. Pence, Who's Afraid of Human Cloning?, Lantham, MD, Rowman \& Littlefield Publishers, Inc., 1997, p. 113. 


\section{Un lujo que no nos podemos permitir}

Jürgen Habermas ya indica en la postdata al Futuro de la naturaleza humana que hay diferencias extremas entre la recepción y el tratamiento en Alemania y Estados Unidos de las cuestiones relacionadas con la manipulación genética y la clonación. Para los pensadores alemanes, los usos de la genética por parte de un estado totalitario todavía son recuerdos vivos. En Estados Unidos, que quizá sea la cuna de los programas eugenésicos estatales, los filósofos no funcionan bajo la presuposición de que el Gobierno favorece el uso de la genética y las tecnologías relacionadas para controlar y seleccionar a la población. Tenemos que ser sensibles a estos dos contextos de mundos de vida tan distintos. Sin embargo, Habermas también ha ofrecido un argumento que apela a las intuiciones y tradiciones de nuestra moral occidental, y de un modo más específico ha articulado su rechazo de cualquier forma de diagnóstico génico preimplantacional en términos de argumentos sobre el futuro de nuestras identidades políticas. Creo, no obstante, que Habermas sucumbe víctima de las críticas que él mismo parece lanzar contra los nietzscheanos en Alemania. Aunque ha intentado trasladar el debate sobre la clonación y otras tecnologías genéticas relacionadas al nivel más concreto de lo moral y lo político, más que al nivel metafilosófico, creo que no ha hecho un movimiento lo suficientemente radical en la dirección de lo concreto y urgente. El mismo Habermas se queda en un nivel demasiado elevado de abstracción. De hecho, y ésta es mi crítica principal, el tipo de argumentación de Habermas en este libro me recuerda demasiado al tipo de argumentación que encontramos en Estados Unidos y que busca moralizar una cuestión que, desde muchos puntos de vista, requiere más nuestra atención jurídica y política. La moralización de las críticas de la clonación o la genómica es un lujo que los intelectuales de los países del Primer Mundo se pueden permitir. Es un lujo, además, que en vez de aclarar los peligros que se presentan, los oculta y oscurece. La clonación, la genómica, la terapia celular, el diagnóstico génico y todas las tecnologías reproductivas genéticamente mejoradas no son sino una rama de una revolución tecnológica más amplia. Jeremy Rifkin ha indicado correctamente que el siglo de la biotecnología al que nos enfrentamos es el producto de la «revolución de la información» ${ }^{27}$. La posibilidad, y logro inminente, de la clonación humana es sólo uno de los múltiples resultados posibles de una revolución tecnocientífica crucial. Los peligros más urgentes, y quizá más graves, a los que nos enfrenta la revolución de la información, de la que la revolución biotecnológica no es más que una parte, tienen que ver con la erosión de los derechos civiles de los ciudadanos, por una parte, y con la transformación de la agricultura por las cosechas genéticamente modi-

${ }^{27}$ Jeremy Rifkin, El siglo de la biotecnología: el comercio genético y el nacimiento de un mundo feliz, trad. de J. P. Campos, Barcelona, Crítica/Marcombo, 1999. 
ficadas, por otra. La revolución de la información ha hecho posible que los gobiernos mejoren sus tecnologías de vigilancia, que tengan un acceso libre $\mathrm{y}$, lo que es más importante y aterrador, incontrolado, a las vidas privadas de los ciudadanos y a sus vidas públicas. Mientras algunos especulan sobre las amenazas a la integridad personal y la inviolabilidad que representa el potencial futuro de la clonación, en este mismo momento en algún lugar de Bonn y Washington, los funcionarios e ingenieros estatales que trabajan para los servicios de seguridad del estado están diseñando formas más ingeniosas aún de extraer datos de la red, de los bancos de datos de los hospitales, bibliotecas públicas, compras electrónicas y navegaciones. Una nueva ola de constitucionalización se ha desatado bajo el impacto y presión de las tecnologías de la información. La respuesta no debería ser cerrar la red, ni tampoco rendirnos simplemente a las nuevas tecnologías de vigilancia estatal. Más bien, debería inaugurarse un nuevo activismo cívico. El segundo grupo de retos tiene que ver con la biotecnologización de la agricultura mundial. El problema, no obstante, no se limita a la aplicación de la biotecnología a la agricultura. También incumbe al desarrollo de un régimen jurídico global que está imponiendo derechos de propiedad intelectual sobre los organismos genéticamente modificados con el fin de forzar un nuevo tipo de colonialismo. Ambos retos no tienen precedentes. Respecto a la biotecnologización de la agricultura, nos encontramos ante la pérdida de diversidad genética de las cosechas, la liberación potencialmente desastrosa de malas hierbas de gran resistencia, y la alteración de los ciclos vitales de la fauna y la flora que sirve de nicho ecológico para el sostenimiento de la agricultura. Mientras escribo, la superficie sembrada con semillas genéticamente modificadas está creciendo a escala mundial. En el año 2001 se habían plantado más de 80 millones de acres de soja genéticamente modificada, además de 20 millones de maíz. De hecho, como se indica en un artículo reciente de National Geographic, «más del 60 por 100 de todas las comidas preparadas que se encuentran en las estanterías de los supermercados estadounidenses - incluyendo pizzas, patatas fritas, galletas, helados, aliños para ensaladas, sirope de maíz y levadura - contienen ingredientes derivados de soja, maíz y colza genéticamente modificadas» ${ }^{28}$. Sin embargo, no hay discusión pública, ni siquiera una Audiencia Constitucional, y menos aún una Comisión Presidencial sobre cultivos genéticamente modificados. Muchos de estos organismos genéticamente modificados, o las llamadas semillas Frankestein, se han lanzado a los supermercados sin una experimentación apropiada, e incluso a pesar de las fuertes protestas de agricultores y gobiernos en Europa, África, India y México. Los cultivos genéticamente modificados son un hecho - los estamos comiendo sin saberlo- . Pero al tiempo que se plantan más y más acres de tierra con cosechas genéticamente modificadas, son menos las industrias o empresas

${ }^{28}$ Véase Jennifer Ackerman, «Food: How Safe? How Altered?», National Geographic, vol. 201, núm. 5, mayo 2002, pp. 2-50, cita de la página 35, estadística de la p. 37. 
agrícolas a cargo de la provisión y suministro de las semillas. En 1995, 24 empresas tenían más del 50 por 100 de las acciones del mercado combinado de la agroindustria. De estas 24 empresas, ocho eran multinacionales. A partir de 1995 se ha producido incluso una mayor consolidación, debido a los movimientos de compra de multinacionales más pequeñas por parte de Monsanto, Dupont y la Fundación Holden ${ }^{29}$. Además, esta monopolización de la biotecnología agrícola en unas pocas transnacionales se agrava por la imposición a través del Acuerdo General sobre Aranceles Aduaneros y Comercio (GATT) y la Organización Mundial del Comercio (OMC) de Derechos de Propiedad Intelectual (DPI) que hacen posible que estas mismas multinacionales impongan y manejen el uso de sus semillas genéticamente modificadas ${ }^{30}$. El colmo de la obscenidad de este nuevo régimen es el intento de Monsanto de introducir lo que se ha denominado «semillas kamikaze», semillas que tienen únicamente un ciclo de vida, obligando a los agricultores a seguir comprando semillas para cada ciclo de plantación. De este modo, está desencadenándose una forma nueva y más sofisticada de colonialismo, un colonialismo que utiliza las armas del régimen jurídico y la tecnociencia al servicio de las multinacionales de las naciones industrializadas del llamado Primer Mundo. Los fundamentos de la modernidad política están siendo socavados no porque quepa la posibilidad de que permitamos la clonación humana, o porque quepa la posibilidad de que permitamos el cribado genético, sino porque la revolución de la información ha extendido nuevas tecnologías que amenazan nuestras nociones de privacidad y responsabilidad, y redefine los términos mismos sobre los que negociamos nuestros mundos de vida. Al mismo tiempo, esta revolución de la información ha transformado la agricultura y la ganadería, acelerando la transición desde una humanidad predominantemente rural a la situación actual, en la que predominan los urbanitas, convirtiendo la producción de comida en otra mercancía. Así, se ha producido una inversión sorprendente: hubo un tiempo en el que el capitalismo dependía de la naturaleza y la colonización de tierras extrañas para proporcionar materia prima para la producción. Ahora el capitalismo transnacional produce naturaleza y las tierras extrañas del mundo deben venir a él para encontrar lo que es «natural». El problema con los discursos moralizantes sobre la clonación humana es que hablar, implícita o explícitamente, sobre «jugar a ser Dios», es

\footnotetext{
${ }^{29}$ Véase Kristin Dawkins, The Gene Wars: The Politics of Biotechnology, Nueva York, Seven Stories Press, 1997, pp. 25-26.

${ }^{30}$ Véase Ph. D. Marc Lappé y Britt Bailey, Against the Grain: Biotechnology and the Corporate Takeover of Your Food, Monroe, Maine, Common Courage Press, 1998, pp. 1-18. Véase también el número especial sobre «Biopiracy \& Biotechnology» de Peace Review, vol. 12, núm. 4, diciembre 2000. Véase también Vandana Shiva, Stolen Harvest: The Hijacking of the Global Food Supply, Boston, South End Press, 1999, y Biopiracy: The Plunder of Nature and Knowledge, Boston, South End Press, 1997.
} 
una «irrelevancia que distrae» ${ }^{31}$. Lo que necesitamos es una discusión renovada sobre quién tiene la propiedad de qué, y quién tiene acceso a, y si podemos utilizar la autoridad de la ley constitucional y la legislación democráticamente sancionada para convertir la «revolución de la información» en una cornucopia social más bien que una caja de Pandora.

${ }^{31}$ Véase David Shenk, «Biocapitalism: What Price the Genetic Revolution?, en Harper's Magazine, vol. 295, núm. 1771, diciembre 1997, pp. 37-45, cita de la página 44. 